Research, Society and Development, v. 9, n. 8, e191985540, 2020

(CC BY 4.0) | ISSN 2525-3409 | DOI: http://dx.doi.org/10.33448/rsd-v9i8.5540

\title{
A importância da prática do futsal na frequência escolar e na motivação dos alunos de uma escola especial
}

The importance of futsal practice in the frequency and motivation of the students of the one special school

\section{La importancia de la práctica futsal en la frecuencia y motivación de los estudiantes de la una escuela especial}

Recebido: 12/06/2020 | Revisado: 16/06/2020 | Aceito: 17/06/2020 | Publicado: 29/06/2020

\section{Rafael Mello Martins}

ORCID: https://orcid.org/ 000-0002-3540-2988

Escola Especial do CERENEPE, Brasil

E-mail: rafael_fico@yahoo.com.br

Franciele Roos da Silva Ilha

ORCID: https://orcid.org/0000-0001-6016-4259

Universidade Federal de Pelotas, Brasil

E-mail: francieleilha@gmail.com

\section{Resumo}

Muitos pais de alunos com deficiência inserem seus filhos em escolas especializadas no intuito de melhorarem os processos de ensino-aprendizagem. Porém, a frequência e a motivação dos alunos na escola envolvem diferentes fatores. Considerando que as práticas corporais possam se constituir em um dos fatores que motivem os alunos e melhorarem a sua frequência na escola, a presente proposta visou averiguar tal questão. O objetivo geral do estudo foi analisar a participação dos alunos de uma escola especial nas diferentes atividades educativas, a partir da vivência do Projeto de Futsal. A metodologia da pesquisa apresentou a abordagem quali-quantitativa. O contexto de pesquisa foi uma Escola Especial localizada em um município do Estado do Rio Grande do Sul. Os sujeitos da pesquisa foram todos os profissionais envolvidos diretamente nos atendimentos dos alunos com deficiência na escola: nove (9) professores de turmas, três (3) profissionais da equipe técnica (duas psicólogas e uma assistente social), três (3) profissionais da equipe diretiva (duas coordenadoras pedagógicas e uma diretora), 60 alunos e 60 pais do projeto do Futsal da Escola Especial. A coleta de dados foi realizada através de um questionário de perguntas fechadas e abertas (misto). Os resultados demonstraram que o Projeto do Futsal é de grande relevância para a 
frequência dos alunos nesta escola, comprovando que nos dias de treinos do Futsal a frequência é acima da média regular. Além disso, esta atividade os mantém motivados no ambiente escolar, ao se inserirem em outras modalidades esportivas, projetos esportivos, musicais e artísticos, melhorando o seu relacionamento na escola, sendo também importante na socialização.

Palavras-chave: Futsal; Frequência; Motivação; Deficiência.

\begin{abstract}
Many parents of students with disabilities place their children in specialized schools in order to improve the teaching-learning processes. However, the frequency and motivation of students at school involve different factors. Considering that body practices can be one of the factors that motivate students and improve their attendance at school, this proposal aimed to investigate this issue. The general objective of the study was to analyze the participation of students from a special school in different educational activities, from the experience of the Futsal Project. The research methodology presented the qualitative and quantitative approach. The research context was a Special School located in a municipality in the State of Rio Grande do Sul. The research subjects were all professionals directly involved in the care of students with disabilities at school: nine (9) class teachers, three (3) professionals from the technical team (two psychologists and a social worker), three (3) professionals from the management team (two pedagogical coordinators and one director), 60 students and 60 parents from the Special School Futsal project. Data collection was performed using a closed and open questionnaire (mixed). The results showed that the Futsal Project is of great relevance to the frequency of students at this school, proving that on Futsal training days the frequency is above the regular average. In addition, this activity keeps them motivated in the school environment, by inserting themselves in other sports, sports, musical and artistic projects, improving their relationship at school, being also important in socializing.
\end{abstract}

Keywords: Futsal; Frequency; Motivation; Deficiency.

\title{
Resumen
}

Muchos padres de estudiantes con discapacidades colocan a sus hijos en escuelas especializadas para mejorar los procesos de enseñanza-aprendizaje. Sin embargo, la frecuencia y la motivación de los estudiantes en la escuela involucran diferentes factores. Teniendo en cuenta que las prácticas corporales pueden ser uno de los factores que motivan a los estudiantes y mejoran su asistencia a la escuela, esta propuesta tuvo como objetivo 
investigar este problema. El objetivo general del estudio fue analizar la participación de estudiantes de una escuela especial en diferentes actividades educativas, a partir de la experiencia del Proyecto Futsal. La metodología de investigación presentó el enfoque cualitativo y cuantitativo. El contexto de investigación fue una escuela especial ubicada en un municipio del estado de Rio Grande do Sul. Los sujetos de investigación fueron todos profesionales directamente involucrados en el cuidado de estudiantes con discapacidades en la escuela: nueve (9) maestros de clase, tres (3) profesionales del equipo técnico (dos psicólogos y un trabajador social), tres (3) profesionales del equipo directivo (dos coordinadores pedagógicos y un director), 60 estudiantes y 60 padres del proyecto Futsal de la Escuela Especial. La recolección de datos se realizó mediante un cuestionario cerrado y abierto (mixto). Los resultados mostraron que el Proyecto de Fútbol Sala es de gran relevancia para la frecuencia de los estudiantes en esta escuela, lo que demuestra que en los días de entrenamiento de Fútbol Sala la frecuencia está por encima del promedio regular. Además, esta actividad los mantiene motivados en el entorno escolar, al insertarse en otros proyectos deportivos, deportivos, musicales y artísticos, mejorando su relación en la escuela, siendo también importante en la socialización.

Palabras clave: fútbol sala; Frecuencia; Motivación; Deficiencia.

\section{Introdução}

A Escola, depois da família, é o espaço primeiro e fundamental para o processo de socialização da criança (MEC, 2007). A educação especial abrange as escolas especiais que alunos com deficiência estão inseridos, prestando um papel fundamental no desenvolvimento dos mesmos, desde o aspecto de socialização até a construção de maior autonomia:

Segundo Cavalcante (2005), educação especial é entendida como a modalidade de ensino que tem como objetivo quebrar as barreiras que impedem a criança de exercer a sua cidadania. $\mathrm{O}$ atendimento educacional especializado é apenas um complemento da escolarização, não substituto. Completando, Bagatini (1992), explica que a escola especial é a instituição destinada a prestar atendimento educacional a educandos com necessidades especiais onde são desenvolvidos currículos adaptados e procedimentos de apoio pedagógico, por pessoas especializadas, usando equipamento e material didático adequado.

No contexto educativo das escolas, incluem-se diferentes componentes curriculares, como a Educação Física. Para Krug (2002), a educação física tem um papel importante, por ser uma disciplina atraente para a maioria dos estudantes, podendo ser usada como uma 
grande fonte de motivação não só para sua aplicabilidade como também se estendendo para outras disciplinas, como para própria vida de um modo geral.

Segundo Galatti \& Paes (2006), a educação física é fundamental para o desenvolvimento integral do aluno e a prática esportiva constitui-se como um meio de socialização. Consolidando esta opinião, Callois (1990) diz que o esporte é importante nas relações sociais.

Nesta mesma direção, Mosquera \& Stobäus (1994) afirmam que através da atividade esportiva o indivíduo desenvolve melhores oportunidades de aprimoramento do comportamento humano.

Cabe destacar que a Educação Física, como disciplina escolar, apresenta diferentes conteúdos, dentre esses a promoção de atividades físicas e esportivas. Da mesma forma que o professor de Educação Física trabalha com tais conteúdos em suas aulas, a escola também pode ofertar atividades extras em outros turnos, como os projetos esportivos. Assim, a educação física tem papel importante para manter os alunos ativos contrapondo um estilo de vida sedentário, proporcionando uma formação integral do indivíduo, sendo também uma disciplina que potencializa o engajamento dos alunos no ambiente escolar.

A Educação Física possui um impacto positivo no pensamento, no conhecimento e ação, nos domínios cognitivos, afetivos e sociais, ou seja, na vida do ser humano como um todo. Entretanto é importante afirmar que o indivíduo plenamente desenvolvido a partir do movimento consegue construir uma vida ativa, saudável e produtiva, criando uma integração segura e adequada e de desenvolvimento harmônico entre corpo, mente e espírito (Serafim, 2008, p.4).

Dessa forma, o esporte, como conteúdo pedagógico na educação formal e não formal, deve ter caráter educativo (Oliveira, 2004).

Neste trabalho a ênfase é dada aos alunos com deficiência, assim, algumas colocações são necessárias quanto a importância da educação física para esses alunos, como o descrito a seguir:

Por desconhecimento, receio ou mesmo preconceito, a maioria dos portadores de deficiências físicas foram (e são) excluídas das aulas de Educação Física. A participação nessa aula pode trazer muitos benefícios a essas crianças, particularmente no que diz respeito ao desenvolvimento das capacidades afetivas, de integração e inserção social. (BRASIL, 1997, p.40). 
A oportunidade da prática esportiva para pessoas com deficiência é de extrema eficácia para a promoção da qualidade de vida das mesmas. Segundo Melo \& López (2002) é a oportunidade de testar seus limites e potencialidades, prevenir as enfermidades secundárias a sua deficiência e promover a integração social do indivíduo.

Nahas (2006) explica que as atividades físicas regulares podem reduzir os sintomas de ansiedade e depressão, promover a socialização e aumentar os níveis e bem-estar geral das pessoas com deficiência. Na mesma linha, Aviz (1998) ressalta que a atividade física e/ou esporte pode significar para o portador de deficiência, o desenvolvimento da autoestima, a melhoria da sua autoimagem, o estimulo a independência, a integração com outras pessoas, uma experiência enriquecedora com seu próprio corpo, além de uma oportunidade de testar suas possibilidades, prevenir-se contra deficiências secundarias e integrar-se consigo mesmo e com a sociedade.

O profissional inserido nessa realidade e no contato direto com essas pessoas demonstra satisfação: "Só quem tem contato com essas crianças percebe que lidar com elas não é difícil. É um privilégio, afirma a professora Simone, da Escola Viva" (CAVALCANTE 2005, p. 44).

Também é papel das escolas e profissionais, inovar no seu planejamento a cada ano oferecendo atividades novas, de grande aceitação e possíveis dentro da realidade desses alunos para manter os mesmos ativos e presentes dentro da escola, tendo em vista que muitos alunos estão presentes há anos dentro da mesma instituição.

Para Rodrigues (2006) a deficiência é uma condição em grande parte construída socialmente, ou seja, a deficiência é como se fosse fruto dos valores decorrentes da sociedade e da cultura. Rosadas (1991) explica que os deficientes apresentam ou possuem as mesmas necessidades que os ditos normais precisam, como por exemplo, as necessidades afetivas, sociais, físicas e intelectivas. Acrescenta, ainda, que essas crianças e adultos têm um grande potencial e que o mesmo deve ser despertado e acreditado.

A partir daí, destaca-se a figura do professor de educação física em proporcionar condições especiais para estimular o desenvolvimento motor e funcional para essa população com necessidade especial.

Sabendo que além dos ganhos físicos a prática esportiva é uma forma de interação social de reconhecer e superar limites e a consequente melhoria da autoestima e posicionamento da pessoa com deficiência no ambiente escolar e na sociedade. Segundo Bracht (2012), o esporte praticado na escola através de modalidades esportivas, prepara e orienta o aluno a ter uma formação e um convívio social. 
Ressalta-se assim, a importância da educação física, atividade física e esportiva para esses alunos, as quais têm um papel fundamental para o seu desenvolvimento. Para tanto, este estudo trouxe o seguinte questionamento: Os alunos do projeto do Futsal da escola especial estudada são mais frequentes e apresentam maior motivação na escola?

O objetivo geral do estudo foi analisar a participação dos alunos nas diferentes atividades da escola a partir da vivência do projeto de futsal. Já os objetivos específicos foram: a) investigar o índice de frequência dos alunos nas atividades da escola a partir da vivência do projeto do futsal; b) investigar o índice de motivação dos alunos do nas atividades da escola a partir da vivência do projeto do futsal.

Esta investigação se faz necessária por diferentes fatores: pelo futsal representar o desporto mais trabalhado, reconhecido e com maior número de adeptos na realidade escolar é a primeira opção dos pais em atividades para os filhos no turno inverso da escola. Este fato reflete no grande número de escolinhas de futsal no nosso país. Situação que não diferente na nossa cidade, sendo então considerada uma ferramenta importante para o sucesso da educação física no ambiente escolar.

O futsal influencia na aprendizagem motora e sócio afetiva dos alunos. Portanto, não se deve esquecer a sua relevante importância para a cultura corporal (Branco \& Kawashima, 2008). O futsal praticado na escola, para cumprir seu papel pedagógico, deve atender as realidades do aluno, tomando-se os devidos cuidados para que sua prática possa contribuir para o desenvolvimento social do aluno (Santos, 2014). Para Filho (2009), o futsal tem um conteúdo valioso e pode ser utilizado de diversas maneiras, atendendo aos objetivos do planejamento escolar. Assim, desconsiderar o futsal nas aulas de Educação Física Escolar é negar a cultura do país.

Este estudo também justifica a sua importância ao incluir o debate acerca da atividade física para aquisição de uma qualidade de vida e, principalmente, para a pessoa com deficiência.

Muitos pais de alunos com deficiência inserem seus filhos em escolas especializadas no intuito de melhorarem os processos de ensino-aprendizagem. Porém, a frequência e a motivação dos alunos na escola envolvem diferentes fatores. Considerando que as práticas corporais possam se constituir em um dos fatores de motivação os alunos e traga melhorias nos índices de frequência na escola, a presente proposta visou averiguar tal questão. 


\section{Metodologia}

A metodologia utilizada nesta pesquisa foi pautada na investigação quanti- qualitativa do tipo estudo de caso. Desta forma, o presente estudo preocupa-se com dados numéricos, mas também com o contexto e relações do fenômeno pesquisado.

A pesquisa mista ou quanti-qualitativa, aqui assumida, trabalha com dados de fácil quantificação e complementa-os com dados subjetivos ou descritivos. É assim definido pelo autor:

Os métodos mistos combinam os métodos predeterminados das pesquisas quantitativas com métodos emergentes das qualitativas, assim como questões abertas e fechadas, com formas múltiplas de dados contemplando todas as possibilidades, incluindo análises estatísticas e análises textuais. Neste caso, os instrumentos de coleta de dados podem ser ampliados com observações abertas, ou mesmo, os dados censitários podem ser seguidos por entrevistas exploratórias com maior profundidade. No método misto, o pesquisador baseia a investigação supondo que a coleta de diversos tipos de dados garanta um entendimento melhor do problema pesquisado (Creswell, 2007, p.p. 34$35)$.

Em relação ao estudo de caso, Araújo (2008) esclarece que se trata de uma abordagem metodológica de investigação especialmente adequada quando procuramos compreender, explorar ou descrever acontecimentos e contextos complexos, nos quais estão simultaneamente envolvidos diversos fatores.

O contexto de pesquisa foi uma Escola Especial localizada em um município do Estado do Rio Grande do Sul, que atende em torno de 250 pessoas (pacientes, alunos e usuários) com deficiência intelectual em três áreas de atendimentos: área da saúde (setor clinico), da educação (setor pedagógico) e assistência social (grupos de convivência) atendendo todas as idades.

Esta escola tem aumentado a sua demanda de usuários, recebendo alunos da rede regular de ensino, com diagnóstico para atendimento especializado, considerando que a rede regular nem sempre está preparada para receber de forma integral, em número e estrutura, os alunos com deficiência. Nela são realizadas diversas atividades pedagógicas, além dos atendimentos especializados no setor pedagógico e nos grupos de convivência nas especialidades de música, educação física, expressão corporal, e diversos outros projetos, como o projeto de futsal.

O projeto de futsal está inserido nesta escola, complementando e enriquecendo as atividades da educação física dentro do conjunto de atividades físicas e esportivas. Estas 
atividades visam ser mais uma ferramenta para além da inclusão, constituindo-se num fator relevante de combate a obesidade, o sedentarismo e aumentando a qualidade de vida desses alunos. Assim, este projeto vem auxiliar nesses objetivos somado as aulas de educação física presente como atendimento especializado na escola em todas as turmas do setor pedagógico e grupos de convivência.

[...] a UNESCO estabelece que a prática da Educação Física é um direito fundamental de todos e que os programas devem dar prioridade aos grupos menos favorecidos no seio da sociedade (Carta Internacional de Educação Física de Desportos 1978); a Educação Física e o Desporto evidenciam o potencial das pessoas portadoras de deficiência, influindo positivamente no processo de alto-imagem e valorização das mesmas pela sociedade; as pessoas portadoras de deficiência têm demandado cada vez mais a participação em atividades de Educação Física, Desportos e Lazer [...] (Carmo, 1991, p. 145).

Além desses objetivos, o projeto do futsal nesta escola especial visa também à formação da equipe da escola para representar a escola em torneios, olimpíadas, gincanas e jornadas esportivas dentro e fora da escola. Um exemplo são as olimpíadas da APAES nas suas etapas regional, macrorregional e estadual, que ocorrem em diferentes cidades do estado do Rio Grande do Sul, além da final nacional e também em outros eventos Paraolímpicos.

O Projeto atende hoje em torno de 60 alunos em três turmas: uma no setor pedagógico (com 20 alunos) e duas nos grupos de convivência com 40 alunos (sendo 25 da equipe masculina e 15 da equipe feminina). Além de promover a qualidade de vida dos alunos, o desenvolvimento de aspectos físicos e motores, trabalha-se com aprendizado das regras do jogo e os educativos de iniciação básicos do desporto.

Os sujeitos da pesquisa foram todos os profissionais envolvidos diretamente nos atendimentos dos alunos com deficiência na escola: nove (9) professores de turmas, três (3) profissionais da equipe técnica (duas psicólogas e uma assistente social), três (3) profissionais da equipe diretiva (duas coordenadoras pedagógicas e uma diretora), 60 alunos e 60 pais do projeto do Futsal.

A coleta de dados foi realizada através de um questionário de perguntas fechadas e abertas (misto) entregue para os alunos, pais, professores, equipe técnica e diretiva da escola.

A investigação com os alunos foi diretamente sobre o seu índice de frequência nos dias de treinos do projeto do Futsal, em relação a outros dias de aulas e atendimentos no setor pedagógico e nos dos grupos de convivência. Também buscou investigar se os alunos iniciaram a prática de outras modalidades esportivas (atletismo, handebol, voleibol e 
basquetebol) e a participação em outros projetos de integração, depois que ingressaram no projeto de futsal.

Para os alunos não alfabetizados o questionário foi feito por meio de entrevista. Com os professores, equipe técnica e diretiva o questionário foi pautado diretamente na frequência desses alunos em suas aulas e nos atendimentos nos dias de treinos de Futsal e também o aumento ou não no aspecto de socialização na escola e nos grupos de convivência dos alunos inseridos no projeto do Futsal.

A investigação e avaliação com os pais foi da participação do filho(a) no projeto de Futsal e buscou analisar a evolução através do projeto, nos aspectos de socialização e participação em outros projetos esportivos, artísticos e musicais dentro da escola.

Os dados obtidos através dos questionários foram analisados inicialmente em três grupos, sendo eles: a) alunos, b) pais, c) professores juntamente com a equipe técnica e diretiva da escola. Após essa etapa, os resultados foram comparados e, através deste, foi possível construir uma tabela e realizar uma análise descritiva, verificando a importância da prática do projeto de futsal na frequência e na motivação do aluno no ambiente escolar. Além de sua integração em outras atividades esportivas, musicais e artísticas.

\section{Resultados e Discussão}

A partir do objetivo desta pesquisa em analisar a participação dos alunos de uma Escola Especial nas diferentes atividades da mesma, investigando o índice de frequência e motivação dos alunos a partir da vivência do projeto de futsal apresenta-se inicialmente alguns apontamentos teóricos das temáticas envolvidas e, posteriormente, os resultados e discussão das informações encontradas.

\section{O fator motivação}

A motivação é um fator de fundamental importância para o aluno ingressar e permanecer na prática de alguma atividade física ou desportiva, obtendo os inúmeros benefícios dessa prática. Segundo Pereira (1992), o ser humano age sempre em função de motivos, sejam estes explícitos ou implícitos. Esses motivos se apresentam com uma forte razão interna que afigura uma necessidade psicológica. 
Entretanto, as pesquisas realizadas na área escolar indicam que os fatores que interferem na motivação do atleta adolescente para o esporte são os motivos internos e externos, como: brincadeiras, desenvolvimento de habilidades, excitação e desafio pessoal, realização e status; liberação de energia ou tensão e amizade. Os meninos valorizam mais a realização e o status e as meninas, as brincadeiras e as amizades (Gouvêa, 1997, p. 169).

Existem dois tipos de motivação: a) a motivação intrínseca, também chamada de motivação pessoal ou inconsciente, é a motivação que vem do prazer que alguém obtém da tarefa em si, da satisfação resultante de completar uma tarefa ou simplesmente de trabalhar nessa mesma tarefa; e, b) a motivação extrínseca: também conhecida por motivação ambiental ou consciente, relacionada a fatores motivacionais externos, traduzidos em recompensas como premiação, dinheiro ou notas (no caso do ensino). Estas recompensas proporcionam a satisfação ou o prazer que a tarefa em si não proporciona (Viegas, 2011).

A motivação tanto intrínseca (fatores internos, interesses e gostos) quanto extrínseca (fatores externos, recompensas ou castigos) tem sido relevante nas aulas de futsal. Ela é maior quando o aluno tem afinidade com o esporte ou quando é parabenizado (Silva, 2012).

Considerando a classificação da motivação em intrínseca (motivado por fatores internos) e extrínseca (motivados por fatores externos) e levando em conta os fatores internos da motivação para o aprofundamento do contexto desse estudo, a motivação intrínseca é assim definida pelos autores:

Quando a motivação é intrínseca, as pessoas não estão focadas em recompensas, elas podem vir, mas como consequência do envolvimento e empenho. Esse tipo de motivação está associado geralmente a comportamentos mais estáveis e duradouros. Também pode levar as pessoas a experimentarem um estado mental diferenciado chamado flow, em que o envolvimento pleno com a atividade e com o momento presente resulta numa sensação de prazer e satisfação únicos e de grande significado pessoal. A vivência de experiências desse tipo pode contribuir para que as pessoas se engajem efetivamente na prática de alguma atividade física ou esportiva (Massarella; \& Winterstein, 2005, p.2).

Uma inovação nos estudos sobre motivação intrínseca é a teoria do "flow", que surgiu dos estudos do Psicólogo americano Mihaly Csikszentmihalyi. Segundo Csikszentmihalyi (1999 apud Weinberg e Gould, 2001, p. 158) ela representa:

As atividades esportivas são potencialmente geradoras do estado de flow. Nelas estão presentes todos os elementos necessários para que o flow ocorra. Constituem atividades que prendem nossa atenção, possuem metas claras, fornecem feedback e 
Research, Society and Development, v. 9, n. 8, e191985540, 2020

(CC BY 4.0) | ISSN 2525-3409 | DOI: http://dx.doi.org/10.33448/rsd-v9i8.5540

representam desafios que devem ser respondidos à altura com determinadas capacidades ou habilidades.

Contrapondo e pontuando uma característica da motivação extrínseca:

A teoria da motivação intrínseca surgiu para explicar o comportamento de pessoas que gastam muito tempo em determinadas atividades sem uma recompensa externa evidente. As recompensas, nesse caso, são inerentes à atividade, ligadas aos sentimentos positivos vivenciados já se a tarefa for realizada na expectativa de recompensas externas, o indivíduo está extrinsecamente motivado. A relevância desse conceito é que a motivação extrínseca tende a deteriora uma vez satisfeita a necessidade ou atingido o alvo extrínseco, a motivação intrínseca tem tendência de ser mais constante (Massarella \& Winterstein, 2005, p. 2).

A motivação extrínseca pode ser a primeira etapa para uma motivação intrínseca duradoura, tendo em vista os elementos extrínsecos encontrados nos discursos, eles são vistos como um prêmio pelo envolvimento com a atividade, não como algo recebido para controlar seu comportamento ou o seu rendimento.

As recompensas extrínsecas podem contribuir para impulsionar uma motivação intrínseca, desde que as pessoas percebam o prêmio como mérito por tal atividade, não como um elemento único e controlador para o seu comportamento (Weinberg \& Gould, 2001).

Avaliado os conceitos e percebendo que o tipo de motivação intrínseca é a motivação desejada aos alunos pesquisados nesse estudo, a partir de então conceituamos a temática da frequência. Sabendo da importância da frequência e estando ela diretamente ligada a motivação, sendo tão relevante para consolidar os objetivos almejados nesse contexto escolar e pautados nesse estudo.

\section{A motivação e a frequência escolar}

A educação física e seus projetos podem fomentar a frequência escolar, construindo nesse contexto um legado de alunos motivados e engajados no ambiente escolar.

Um aluno motivado envolve-se mais no processo de aprendizagem, persevera em tarefas difíceis, mesmo tendo que fazer esforço, procurando desenvolver novas capacidades e mostra-se encorajado e orgulhoso com os seus resultados (Guimarães \& BoruchovitcH, 2004).

A Educação Física Escolar, amplamente reconhecida como eficiente ferramenta de inclusão social (Brasil, 1996; Darido, 2004) é apresentada neste contexto como um conteúdo 
possível de ser adaptado às necessidades laborais deste público específico com deficiência, contribuindo para facilitar o vínculo do aluno com a escola e diminuindo os índices de evasão escolar. Os alunos motivados são mais engajados no ambiente escolar e por consequência possuem maior frequência.

Para Oliveira (1999), a motivação deve ser vista como uma forma de alcançar o sucesso escolar e para tal é necessário que os alunos sintam em casa e na escola um ambiente favorável aos seus interesses pessoais. Na mesma linha, para Monteiro (2010) a motivação e o rendimento escolar influenciam-se mutuamente, pois um aluno com bons resultados vai sentir maior interesse pela escola e, consequentemente um aluno motivado vai persistir em direção aos seus objetivos escolares.

Os projetos e atividades complementares no âmbito escolar são vistos como ferramentas para esse envolvimento escolar. Os alunos frequentes e ativos na escola e motivados de forma intrínseca na educação física e nos seus projetos esportivos e também envolvidos nas outras atividades no ambiente escolar serão favorecidos pelos benefícios da atividade física praticada de forma regular além de incorporarem uma formação crítica e ampla de utilidade para vida.

Com tais considerações, inicia-se a apresentação das informações coletadas. Em relação aos alunos, foram entregues os questionários para todos participantes do projeto futsal, obtendo-se um retorno de 58 dos 60 questionários entregues. Esses 60 alunos são divididos em três grupos equivalentes, os quais seguem assim organizados nas três turmas de futsal da escola: Futsal Masculino (dos Grupos de convivência), Futsal Feminino (dos Grupos de convivência) e Futsal Masculino (do Setor Pedagógico).

Na turma de meninos dos grupos de convivência, a frequência no dia dos treinos de futsal é maior comparada aos outros dias de atendimentos (70\%). A maioria ingressou na pratica de outras modalidades esportivas $(79 \%)$ e de atividades de integração artísticas e musicais (70\%), já participando de competições esportivas pela escola (83\%).

$\mathrm{Na}$ turma de meninos do setor pedagógico, os resultados foram semelhantes aos dos meninos dos grupos de convivência. A frequência no dia do futsal é maior comparada a outros dias de atendimentos (84\%). A maioria já ingressou na prática de outras modalidades esportivas $(73 \%)$ e já participou de eventos esportivos representando a escola (78\%). Porém, um menor número de alunos afirma ter ingressado também em alguma atividade de integração artísticas e musicais nesse período (52\%).

A turma das meninas, diferentemente aos índices das turmas dos meninos mostrou frequência parecida no dia do futsal comparado aos outros dias de atendimento (60\%). Porém, 
a maioria afirma ter ingressado na prática de outras modalidades esportivas (80\%) e também de integração artísticas e musicais (86\%) nesse período, bem como a participação de eventos esportivos escolares $(86 \%)$.

Com base nestas informações, percebe-se o aumento da frequência na escola nos dias do projeto futsal, assim como o ingresso em outras atividades a partir do ingresso neste projeto. Para Lawther (1973), o gosto pela pratica é de suma importância para a permanência de um indivíduo em uma modalidade esportiva, pois o valor educacional, o valor recreativo e o valor de saúde mental existente nos esportes, tendem a diminuir quando a atividade não é divertida.

Holland \& André (1987) afirmam que a participação nos projetos escolares promove o desenvolvimento pessoal e social do aluno, e também se verifica um aumento em vários aspectos como o autoconceito, a identificação com a escola e a autoestima. Na mesma linha Marsh (1992) indica que esses projetos escolares levam, a um aumento do interesse do aluno face à escola, o que conduz a um melhor rendimento nesse contexto.

Os altos índices de frequência no ambiente escolar, aspecto fundamental para o sucesso do trabalho com os alunos nesse contexto, remete a pensar que o projeto motiva os alunos para a prática de atividades físicas e esportivas e promove a motivação para a participação em outros projetos e atividades da escola, contribuindo com o desenvolvimento motor, social, afetivo dos alunos com deficiência.

Cabe destacar, que o tipo de motivação responsável para esses alunos não abandonar a prática do futsal e adentrar em outras modalidades, aponta para motivação intrínseca como fator preponderante.

Quanto aos pais, foram entrevistados os 60 pais dos alunos do projeto do futsal, com um retorno de 53 dos 60 questionários entregues. Os resultados mostraram que todos os pais avaliam como importante a prática do futsal pelo seu filho(a) (100\%), e a maioria desses pais afirmam motivar a participação do filho(a) nessa prática (96\%). A maioria também observa maior frequência no dia dos treinos de futsal comparados aos outros dias (83\%), bem como observa melhora na socialização do filho(a) com a participação no projeto do futsal (92\%) . E mais da metade apontou o ingresso do seu/sua filho(a) em outra modalidade esportiva e outras atividades de integração artísticas e musicais, a partir do ingresso no projeto do Futsal (60\%).

A aproximação da família com a escola é fundamental para o sucesso pedagógico nesse sentido, Marchesi (2004) nos diz que a educação não é uma tarefa que a escola possa realizar sozinha sem a cooperação de outras instituições e, a nosso ver, a família é a instituição que mais perto se encontra da escola. Sendo assim se levarmos em consideração 
(CC BY 4.0) | ISSN 2525-3409 | DOI: http://dx.doi.org/10.33448/rsd-v9i8.5540

que Família e Escola buscam atingir os mesmos objetivos, devem elas comungar os mesmos ideais para que possam vir a superar dificuldades e conflitos que diariamente angustiam os profissionais da escola e também os próprios alunos e suas famílias.

No espaço reservado as observações do questionário, a satisfação dos pais com os atendimentos oferecidos pela escola e a afirmação de que a Escola Especial é o único lugar que seus filhos praticam esportes ou qualquer atividade física aparece com muita frequência, podendo ter um aprofundamento num futuro estudo a questão dos espaços públicos e adaptados para atividade física e prática esportiva da pessoa com deficiência.

"Aluna A adora toda modalidade esportiva, tudo que mexe com o corpo. E eu to muito feliz com tudo que a escola oferece. Obrigado a todos. Beijos" (Pai 1).

"Eu achei muito importante a pratica do futsal pois a Aluna B sempre fala que quarta é o dia do Futsal das meninas e com muito gosto, feliz. Eu então a mãe não tenho nem palavras para agradecer pois em casa ela é muito parada este tipo de atividade é muito bom para eles se mexerem. O esporte é sempre muito bom para o corpo e para a mente. Meus parabéns e muito obrigado!" (Pai 2).

Quanto aos profissionais da escola, foram entregues quinze (15) questionários sendo nove (9) para professores titulares de turmas três (3) para equipe técnica (dois para psicólogas um para assistente social) e três (3) para equipe diretiva (dois para coordenadoras pedagógicas e um para diretora) tendo o retorno de $100 \%$ dos questionários.

Todos avaliam como importante a participação (100\%) e motivam a prática do projeto do futsal (100\%). A maioria percebe uma maior frequência nos dias do futsal comparados aos outros dias de atendimento (93\%), e observam melhora na socialização desses alunos na escola, melhorando o relacionamento no ambiente escolar (93\%). A maior parte apontou o ingresso desses alunos em outra modalidade esportiva, musical ou artística, posterior à entrada no projeto de futsal $(86 \%)$.

Somente um alinhamento entre os professores juntamente com coordenação pedagógica e a direção da escola para alavancar projetos com êxito na sua concepção pedagógica e no que tange a educação física não é diferente. Nessa direção, Libâneo (2001) nos diz que as escolas podem traçar seu próprio caminho envolvendo professores, alunos, funcionários, pais e comunidade próxima que, se tornam corresponsáveis pelo êxito da 
instituição. É assim que a organização da escola se transforma em instância educadora, espaço de trabalho coletivo e aprendizagem.

\section{Considerações Finais}

Com a presente pesquisa pode-se constatar a relevância do estudo dos fatores que levam as pessoas com deficiência a estarem inseridas ou pouco inseridas em atividades físicas no seu cotidiano na escola especial, para a elaboração de iniciativas para manter estes alunos mais ativos.

O Projeto do Futsal da Escola Especial estudada é de grande relevância para a frequência na escola, comprovando que nos dias de treinos do Futsal a frequência é acima da média regular desses alunos, e também os mantêm motivados no ambiente escolar, ao se inserirem em outras modalidades esportivas, projetos esportivos, musicais e artísticos. Além de melhorarem o relacionamento na escola, sendo também importante na socialização.

Para Massarella \& Winterstein (2009, p.65):

Os Profissionais de Educação Física podem tem maior possibilidade de êxito em suas intervenções se reconhecerem os motivos determinantes do comportamento das pessoas, identificando quais reforçam ou inibem o comportamento que desejam incentivar. As razões que se contrapõem ao comportamento de engajamento com relação à atividade devem ser compreendidas e trabalhadas, para que não levem o indivíduo a abandonar a prática.

Diante destas constatações, ressalta-se a importância de promover diferentes atividades físicas e/ou esportivas nas escolas especiais, possibilitando benefícios similares aos comprovados neste estudo, assim como possibilitar outras formas de aprendizagem e desenvolvimento dos alunos.

\section{Referências}

Araújo, C. et al. (2008). Estudo de Caso. Métodos de Investigação em Educação. Instituto de Educação e Psicologia, Universidade do Minho. Recuperado de http://grupo4te.com.sapo.pt/estudo_caso.pdf> 
Aviz, C.C (1998). A criança portadora de necessidades educativas especiais e sua inclusão no ensino regular nas aulas de Educação Física (Monografia de Especialização).

Universidade de Brasília, Brasília, DF, Brasil.

Bagatini, V. (1983). Curso Nacional de Educação Física para Professores de Excepcionais, 8., Porto Alegre. Grafosul.

Baseggio, T.S. (2011). Oficinas sócio-educativas de futsal como ações complementares no processo educacional. Ebookbrowse.

Bracht, V. (1997). Educação física e aprendizagem social. 2. ed. Porto Alegre: Magister.

Branco, M. de F. \& Kawashima, L. B. (2008). A pedagogia do futsal no contexto educacional da escola. Lecturas, Educación Física y Deportes, Revista Digital - Buenos Aires - Año 13 $\mathrm{N}^{\circ}$ 119. Recuperado de http://efdeportes.com/efd119/apedagogia-do-futsal.htm

BRASIL, (1996). Lei de Diretrizes e Bases da Educação Nacional, nº 9394/96. MEC. Brasília.

BRASIL, (1997). Parâmetros curriculares nacionais: Educação Física. Secretaria de Educação Fundamental. Brasília: MEC/SEF.

Caillois, R. (2000). Os jogos e os homens. 4. ed. Porto: Cotovia.

Carmo, A. A. do. (1991). Deficiência Física: A sociedade brasileira cria, "recupera” $e$ discrimina. Brasília: Secretaria dos Desportos.

Cavalcante, M. (2005). A escola que é de todas as crianças. Nova Escola, v. 20, n. 182.

Creswell, J. W. (2007). Projeto de pesquisa: métodos qualitativo, quantitativo e misto. Porto Alegre: Artmed.

Csikszentmihalyi, M. (1999). A descoberta do fluxo: a psicologia do envolvimento com a vida cotidiana. São Paulo: Rocco. 
Darido, S.C. (2004). A educação física na escola e o processo de formação dos não praticantes de atividade física. Rev. Bras. Educ. Fís. Esp, São Paulo, 08(01),.61-80.

Filgueira, F. M. (2006). Aspectos físicos, técnicos e táticos da iniciação ao futebol. Lecturas, Educación Física y Deportes, Revista Digital, Buenos Aires, ano 11, № 103. Recuperado de https://www.efdeportes.com/efd103/iniciaciao-futebol.htm

Filho, C.R.C. (2009). Futsal como tema da educação física escolar. (Trabalho de Conclusão de Curso de graduação). Faculdade de Educação Física de Sorocaba, Sorocaba, SP, Brasil.

Galatti, R. L., \& Paes, R. R. (2006). Fundamentos da pedagogia do esporte no cenário escolar. Movimento \& Percepção, Espírito Santo do Pinhal, 6(9), 16-25 jul.-dez.

Gouvêa, F. (1997). A motivação e o esporte: uma análise inicial. Buriti. Psicologia do Esporte, Campinas: Alínea.

Guimarães, S. E. R., \& Boruchovitch, E. (2004). O estilo motivacional do professor e a motivação intrínseca dos estudantes: Uma perspectiva da teoria da autodeterminação. Psicologia: Reflexão e Crítica, 17(2), 143-150.

Holland, A. \& Andre, T. (1987). Participation in extracurricular activities, in secondary school: What is Known, what need to be Known? Review of Educational Researsh, 57, 437466.

Krug, H.N. (2002). Educação Física Escolar: Temas Polêmicos, a motivação nas aulas de Educação Física Escolar. Cadernos de ensino, pesquisa e extensão. Santa Maria: UFSM.

Lawther, L. (1973). Psicologia desportiva. Rio de Janeiro: Fórum.

Libâneo, J.C. (2001). Organização e gestão da escola: teoria e prática. Goiânia: Editora Alternativa. 
Marchesi, Á., \& Gil, H. C. (2004). Fracasso Escolar: uma perspectiva multicultural. Porto Alegre: ARTMED.

Marsh, H. W. (1992). Extracurricular activities: Beneficial extension of the traditional curriculum or subversion of academic goals? Journal of Educational Psychology, 84, 553562.

Massarella, F. L. \& Winterstein, P. J. (2009). A Motivação Intrínseca e o Estado Mental Flow em Corredores de Rua, Porto Alegre, Revista Movimento.

Massarella, F. L. \& Winterstein, P. J. (2005). Motivação intrínseca e estado de flow no esporte e na atividade física. In: Congresso de Ciência do desporto da faculdade de educação física da Universidade Estadual de Campinas, 1,. Anais... Campinas: UNICAMP, Murray, E. J. Motivação e emoção. Rio de Janeiro.

Melo, A.C.R., \& López, R.F.A. (2002). O Esporte Adaptado. Lecturas, Educación Física y Deportes, Revista Digital - Buenos Aires - Año 8 - N 51. Recuperado de https://www.efdeportes.com/efd51/esporte.htm

Mosquera, J. J. M., \& Stobäus, C. D. (1994). Psicologia do desporto. Porto Alegre: Edufrgs.

Monteiro, D. R. B. (2010). Causas de (In)Sucesso Escolar: estudo de caso de uma escola do concelho de Vila Real. não publicada (Dissertação de Mestrado). Universidade de Trás-osMontes e Alto Douro: Vila Real.

Nahas, M. V. (2006). Atividade Física, saúde e qualidade de vida: conceitos e sugestões para um estilo de vida ativo. 4. ed. rev. e atual. - Londrina: Midiograf.

Oliveira, V., \& Paes, R. R. (2004). A pedagogia da iniciação esportiva: um estudo sobre o ensino dos jogos desportivos coletivos. Lecturas, Educación Física y Deportes, Revista Digital - Buenos Aires - Año 10 - N 71. Recuperado de https://www.efdeportes.com/ efd71/jogos.htm 
Pereira, M.H.S. (1992). A motivação na aprendizagem e ensino em Educação Física. (Monografia de Especialização). Universidade Federal de Santa Maria, Santa Maria, RS, Brasil.

Oliveira, J. (1999). Psicologia da Educação: Escola, Aluno e Aprendizagem. Lisboa: Editorial Presença.

Rodrigues, D. (2006). Atividade Motora Adaptada: A Alegria do Corpo. São Paulo: Artes Médicas.

Rosadas, S. de C. (1991). Educação Física Especial para Deficientes. 3. ed. Rio e Janeiro: Atheneu.

Santos, W. J. dos. (2014). Educação física nas quatro linhas: futsal como fator de socialização entre alunos (Trabalho de Conclusão de Curso de Especialização). Universidade Tecnológica Federal do Paraná, Medianeira, Paraná, Brasil.

Serafim, P.A. et al. (2008). Educação Física e psicomotricidade: uma relação fundamental no desenvolvimento humano. Laboratório de Atividades Lúdico-Recreativas (LAR) da UNESP/Presidente Prudente.

Silva, F. R. da. (2012). Níveis de motivação de escolares nas aulas de educação física na cidade de Candeias do Jamari - RO (Trabalho de Conclusão de Curso de Graduação). Universidade Federal de Rondônia, Porto Velho, Rondônia, Brasil.

Viegas, L. Motivação intrínseca e motivação extrínseca. Recuperado de https://linoeportfolio.wordpress.com

Weinberg, R. S., \& Gould, D. (2001). Fundamentos da Psicologia do Esporte e do Exercício. Porto Alegre: Artmed.

\section{Porcentagem de contribuição de cada autor no manuscrito}

Rafael Mello Martins - 80\%

Franciele Roos da Silva Ilha - 20\% 